Роман Абрамов, Ксения Антонова

\title{
РЕГИОНАЛЬНЫЕ МЕДИА О СОЦИАЛЬНОЙ АДАПТАЦИИ ВЫПУСКНИКОВ ДЕТСКИХ ДОМОВ: ТЕМАТИЧЕСКИЙ АНАЛИЗ ПУБЛИКАЦИЙ ЗА ПЕРИОД 2014-2015 ГГ.
}

\begin{abstract}
Статья характеризует образ выпускников детских домов, формируемый СМИ. С помощью автоматизированного мониторинга средств массовой информации «Медиалогия» проанализированы тематические публикации в семи регионах: Москва, Санкт-Петербург, Иркутск, Калининград, Новосибирск, Тверь, Ярославль. Целевую выборку для текстового анализа составили первые сто статей, с наивысшим рейтингом повторного цитирования и републикаций. Анализ позволил построить тематическую карту освещения социальной адаптации выпускников детских домов. Публикации в основном сосредоточены на вопросах прав и льгот (в том числе и на получении жилья выпускниками при достижении совершеннолетия), на организации помощи в адаптации к самостоятельной жизни после выпуска из детского дома со стороны государства, НКО и частных инициатив волонтеров. На основе материалов публикаций, связанных с личными и обобщенными историями выпускников детских домов, осуществлена тематическая типологизация медиа-образов представителей этой социальной группы: позитивный-самостоятельный («успешно адаптированный выпускник детского дома, добившийся всего сам»), позитивный-пассивный («взрослый ребенок»), негативный-самостоятельный («проблемная часть общества», девиант) и негативный-пассивный («детдомовец» как социальная стигма). Отмечается, что именно «пассивные» медийные образы наиболее распространены в прессе, они стигматизируют выпускников детского дома, позиционируя их как неадаптированных к «реальной» жизни. «Пози-
\end{abstract}

Роман Николаевич Абрамов - к.с.н., доцент департамента социологии НИУ ВШЭ, старший научный сотрудник Института социологии РАН, Москва, Россия. Электронная почта: rabramov@hse.ru

Ксения Александровна Антонова - аспирант факультета социальных наук НИУ ВШЭ, Москва, Россия. Электронная почта: ksantonova@yandex.ru 
тивный-самостоятельный» медийный образ встречается редко, как правило, только в контексте построения успешной карьеры. Данный образ соотносится с конкретными индивидуальными биографиями, которые становятся материалом для публикаций, в то время как остальные медийные образы лишены личностной или гендерной характеристики. Формируемая СМИ «типичная» траектория социализации выпускника не учитывает применяемые современные педагогические и психологические практики, связанные с индивидуальной работой воспитателей и социальных работников с сиротами, готовящимся к выпуску из детского дома или интерната. Показано, что основной корпус материалов, посвященных выпускникам детских домов не отражает всего разнообразия проблем и вызовов, стоящих перед ними.

Ключевые слова: выпускники детских домов, сироты, социальная адаптация, социальные службы

DOI: $10.17323 / 727-0634-2017-15-3-421-434$

Исследования показывают, что выпускники детских домов сталкиваются со сложностями адаптации к самостоятельной жизни после выпуска: отмечается неумение управлять своей личной жизнью и бытом, проблемы с устройством на работу, сложности с установлением социальных контактов, одиночество (Назарова 2000; Гребенникова, Фирсова 2009; Дутова 2013; Шогенова и др. 2016). Проблемы социализации и социальной адаптации выпускников детских домов в России связываются с различными причинами: со спецификой организации пребывания детей и подростков в детских домах (Коноплева, Ларин 2014; Абдрашитова, Паточкина 2015), жесткой регламентацией и вынужденным коллективизмом, отсутствием образцов жизни в условиях семьи. Социальная адаптация при этом определяется как готовность и умение молодого человека после выхода из стен детского дома к самостоятельному проживанию. Это включает навыки бытового самообслуживания, коммуникации с представителями различных социальных групп не только внутри, но и за пределами детского дома, способность выстраивать позитивные отношения со сверстниками, ведение здорового образа жизни. По крайней мере в первые годы самостоятельной взрослой жизни выпускник детского дома особенно нуждается в сопровождении со стороны социальных служб и психологов. Между тем, в настоящее время нет программы социально-психологической и педагогической помощи выпускникам детских домов и интернатов (Миночкина 2012: 166), хотя некоторые эксперты предлагают создать институт социальной адаптации детей-сирот с опорой на международный опыт и нормы в области защиты прав детей, лишенных родительского попечения (Еременко 2014: 290). Кроме этого, проблемной остается сфера правового регулирования жилищных прав выпускников детских домов (Розуван, Редикульцева 2013). 
В последние годы тема детских домов и детей-сирот в России привлекла широкое общественное внимание, а проблема устройства детейсирот и детей, оставшихся без попечения родителей, рассматривается государством в качестве ключевого вопроса социальной политики в области семьи и детства (Бирюкова и др. 2013, Ярская-Смирнова и др. 2015). Детские дома и дети-сироты являются одним из направлений частной и корпоративной благотворительности. До недавнего времени в адрес системы воспитательных и образовательных учреждений для детей-сирот имела место критика со стороны экспертного сообщества, журналистов и гражданских активистов ${ }^{1}$. В частности, говорилось об архаичных педагогических моделях работы с детьми-сиротами, устаревшей материальной базе, отсутствии заботы государства и общества о судьбах выпускников детских домов. Начиная с 2011 г., публичные дискуссии произвели дополнительный импульс к развитию данной тематики. Во-первых, заявления и меры на высоком официальном уровне были ориентированы на поддержку активной семейной политики, связанной с традиционными семейными ценностями, материнством и детством. Примером может послужить подписанный президентом РФ 28 декабря 2013 года указ «О некоторых мерах по реализации государственной политики в сфере защиты детей-сирот и детей, оставшихся без попечения родителей». Во-вторых, тема детейсирот обрела яркую политическую окраску после принятия «Закона Димы Яковлева» (Федеральный закон 2012), который запретил зарубежным гражданам усыновлять детей из России, вызвав неоднозначную реакцию экспертного сообщества и широкой общественности.

Таким образом, жизнь детей-сирот и тема адаптации выпускников детских домов во взрослой жизни время от времени привлекает внимание СМИ, которые формируют медийные образы детей-сирот и выпускников детских домов. Что, в свою очередь, может влиять как на восприятие этой группы в обществе, так и на государственную социальную политику. Именно поэтому характеристика медийных образов выпускников детских домов становится актуальной исследовательской задачей. При этом мы видим проблему в упрощении этих образов, т.е. идеализацию либо криминализацию сирот в медиа: общественной огласке предаются, как правило, благотворительные акции или криминальные случаи, однако, ни те, ни другие не отражают повседневную жизнь.

В статье отображен один из этапов исследования «Траектории социальной и профессиональной адаптации выпускников детских домов»

\footnotetext{
${ }^{1}$ Одним из ярких художественных произведений, критикующих порядки в детских домах стала повесть Рубена Давида Гонсалеса Гальего «Белое на черном», опубликованная в 2002-м году и ставшая лауреатом премии «Букер - Открытая Россия» 2003 г. Полудокументальная повесть о жестокости создала общественный резонанс и заставила обратить внимание общественности на проблемы российских детских домов. В 2009 г. по повести поставлен спектакль в МХТ им. Чехова
} 
под эгидой фонда «Дорога вместе» в рамках проекта Центра фундаментальных исследований, а именно обзор активности медиа в регионах России по теме профессиональной и социальной адаптации выпускников детских домов за 2014-2015 гг. В рассмотрение включены семь регионов: Москва, Санкт-Петербург, Иркутск, Калининград, Новосибирск, Тверь, Ярославль. Их отбор осуществлялся с учетом места региона в рейтингах социальноэкономического положения (I и II квартили рейтинга) и состояния инвестиционного климата (II и IV группы), а также наличия в регионе специальных программ помощи детям-сиротам. Цель анализа - реконструкция и типологизация медийных образов детей-сирот и выпускников детских домов в региональных медиа.

\section{Методика анализа и данные}

Для отбора публикаций использовалась база данных системы автоматизированного мониторинга средств массовой информации «Медиалогия», предоставляющую онлайн доступ к базе СМИ (порядка 92 млн источников, взвешенных по регионам и отраслям) с возможностью производить самостоятельный мониторинг СМИ и экспресс-анализ полученных сообщений. Целевую выборку для тематического текстового анализа составили первые сто статей из новостных интернет-изданий, с наивысшим рейтингом цитирования и републикаций. В ходе анализа применялась техника открытого кодирования (см. Charmaz 2006: 57), предполагающая самостоятельное ознакомление с материалами статей из выборки, определение категорий (тематики публикаций) и их дальнейшее наполнение кодами для выявления специфики на региональном и содержательном уровне. Кодирование осуществляется по параграфам по принципу in vivo: кодами становятся названия организаций, благотворительных фондов и государственных программ, социальных проектов, а также формулируются проблемные области (например, код «получение жилья» или «обеспечение занятости»). Выявленные коды позволили составить тематическую карту, иллюстрирующую контексты, в которых медиа освещают выпускников как представителей отдельной социальной группы, а совокупность кодов в рамках одной публикации позволила воссоздать различные медийные образы выпускников.

Генеральную совокупность для анализа составили 736 публикаций (с учетом повторных публикаций - 1036). Самым активным регионом по количеству публикаций является Санкт-Петербург (425 статей из общей совокупности, см. рис.1), однако следует отметить, что порядка четверти публикаций в этом регионе посвящены прошедшим в исследуемый период выборам уполномоченного по правам ребенка в Санкт-Петербурге. Далее следует Москва (192 статьи), Новосибирск (155), Иркутск (104), Тверь (91), Ярославль (37) и Калининград (32). 


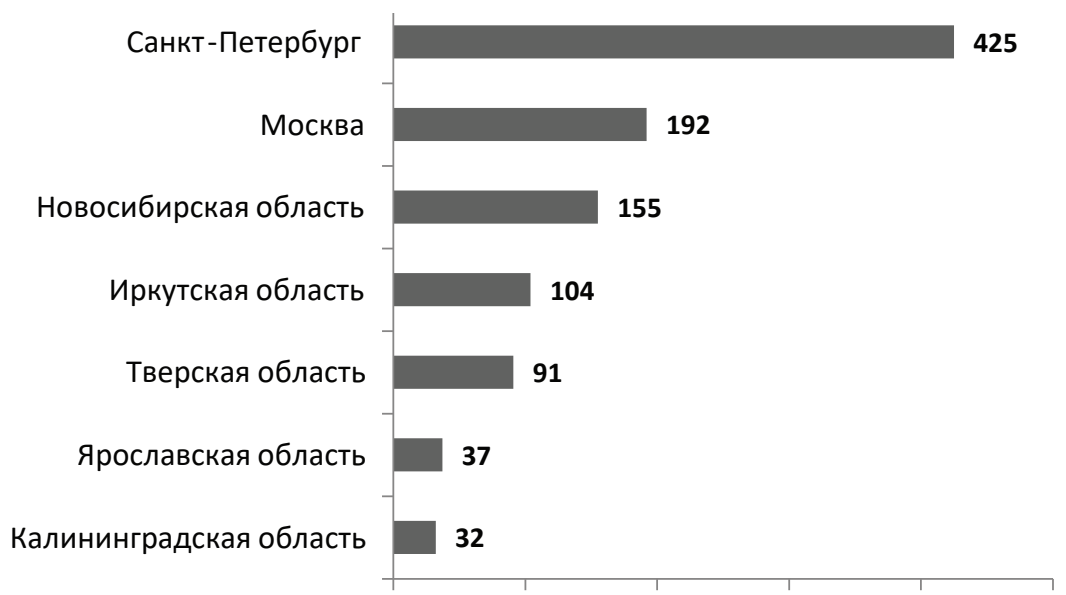

Рисунок 1. Распределение статей по регионам

\section{Медийные образы выпускников детских домов: «детдомовцы» и «взрослые дети»}

В региональных изданиях описываются случаи «личных историй» выпускников детских домов, как персонализированных, так и анонимизированных, на основе которых разработана типологизация медиа-образов представителей этой социальной группы: позитивный-самостоятельный («успешно адаптированный выпускник детского дома, добившийся всего сам»), позитивный-пассивный («взрослый ребенок»), негативный-самостоятельный («проблемная часть общества», девиант) и негативный-пассивный («детдомовец» как социальная стигма). Эти образы проявляются в контексте различных элементов (см. рис.2) и механизмов (категория «Помощь в адаптации») социальной интеграции выпускников в самостоятельную жизнь вне стен детского дома.

«Позитивные» образы выпускников конструируются через характеристику совокупности условий, способствовавших их успешной адаптации к самостоятельной жизни. Так, позитивно-самостоятельный образ в СМИ отражен посредством акцентирования на личных качествах выпускника, характеризующих его как хорошего работника: целеустремленности и трудолюбия и источника происхождения этих качеств (природные черты характера либо результат воспитательной работы сотрудников детского дома). Позитивнопассивный образ представлен как «успешный результат» работы социальных служб, не затрагивающий личных достижений или амбиций самого выпускника. Этот образ подразумевает следование определенной стратегии, которую выработали для него/нее или за него/нее воспитатели детского дома: получение среднего профессионального или высшего образования 
(с заселением выпускника в общежитие, предоставленного образовательным учреждением), формирование заинтересованности в построении карьеры в ходе работы с воспитателями и социальными педагогами, дальнейшее трудоустройство и получение жилья после выпуска из детского дома.

\section{Жилье}

Предоставление квартир выпускникам детских домов

Переезд в большой город из регионов

Точечное заселение

Адресная работа на местах

Неприятие соседями выпускника детского дома

Нарушение законов органами опеки

Проблемы с получением жилья

Угроза мошенничества

Факт мошенничества в отношении

выпускника детского дома

\section{Paбoma}

Обеспечение занятости

Система общественных обязанностей выпускников детских домов

Защищенное производство

Предоставление наставников

\author{
Участники \\ Выпускники детских домов и интернатов \\ Благотворительные фонды \\ Движения

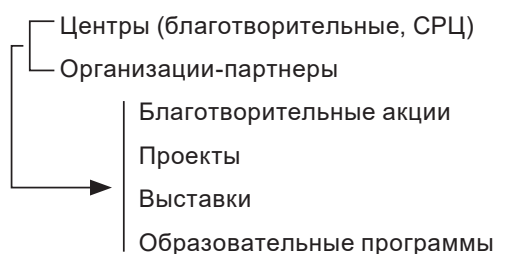

\section{Ресурсы}

Конкурс социальных проектов

Материальная помощь

Поддержка из бюджета

Волонтерство

\section{Помощь в адаптации}

Программа социальной адаптации выпускников детских домов

Постинтернатное сопровождение

Обучение навыкам самообслуживания

«Тренировочная квартира»

Рисунок 2. Тематическая карта по выборочной совокупности публикаций

По сути, это путь «советского простого человека», как его описывал, например, Юрий Левада с коллегами (Левада 1993), когда система детских домов только складывалась и была адаптирована для борьбы с беспризорностью и воспитания «детей войны» для нужд социалистического государства - то, что в одной из включенных в анализ публикаций было названо «трудотерапией по системе Макаренко» (Новосибирский городской сайт, 24.02.2014). В СМИ также описываются случаи, когда выпускники детских домов устраиваются работать в организации, которые напрямую взаимодействуют с детскими домами и интернатами. Впрочем, это скорее единичные примеры, которые не стали повсеместной практикой, так как частные компании не готовы системно и масштабно работать с выпускниками детских домов в отношении их дальнейшего трудоустройства. 
Особенностью репрезентации негативных образов выпускников и детей-сирот является воспроизводимая в медиа установка на социальнопсихологическую пассивность выпускника, которая раскрывается, в том числе, через описание того, как организована деятельность социальных работников в детских домах. Позиция «помощи» воспитаннику детского дома трансформируется в «обеспечение» - то есть опеку, не предусматривающую самостоятельных решений, что выражается не только в материальной форме (пособие, квартира, сбор денег, вещей и игрушек), но и на уровне практик взаимодействия:

Внутри учреждения ребята находятся на полном обеспечении. В реальную жизнь они попадают совсем детьми - по уровню социальной адаптации. И в своем развитии они здорово уступают даже тем детям, которые живут в очень обеспеченных семьях и не знают досконально бытовой практики, но при этом все равно сталкиваются с жизнью, слыша родительские разговоры (Вести-1, 12.11.2015).

Согласно публикациям медиа, воспитательные практики в детском доме далеки от механизмов первичной социализации в семье, что в значительной мере и продуцирует социальную пассивность этой группы. В радикально негативном ключе медийный образ выпускника детского дома переведен в стигму - «детдомовец» (отсылка к советскому дискурсу 1920-1930-х гг., примеры которого можно найти, например, в романе «Республика ШКИД»). Образ «детдомовца» - априори пассивный и слабый, нередко склонный к девиантному поведению и становящийся фактически безвольным иждивенцем общества из-за постоянной нужды в социальной и материальной поддержке:

Если выпускник после училища на работу не устраивается, то он идет в Службу занятости, становится на учет и полгода получает пособие в сумме средней по региону зарплаты. После училища и такого полугода жизни человеку, толком работать не умеющему и немотивированному, чрезвычайно тяжело сдвинуть себя с места, чтобы пойти трудится за 12-18 тыс. рублей (Фонтанка, 8.12.2014).

Негативные образы выпускников воспроизводятся СМИ в различных контекстах, включая сферу труда, экономических отношений и частной жизни. Например, посредством медиа формируется представление о выпускниках как недобросовестных жилищных собственниках, которые склонны разрушать имеющееся у них жилье и мебель, то есть самостоятельно ухудшающих условия для проживания:

В вопросе квартир есть проблема с выпускниками детских домов, которые за короткое время приводят их в непригодное для проживания состояние, потому что не приспособлены к самостоятельному существованию. На это Министерство [Социального развития] обратит свой взгляд и начнет реорганизацию служб опеки и попечительства (Столица FM, 24.01.2015). 
Сконструированный негативный образ выпускника часто связывается в СМИ с образом «пассивного правительства». Так, в медиа проблематизируется ситуация социальной сегрегации выпускников детских домов, а также ошибки местных властей при предоставлении жилья выпускникам, заключающиеся как в бюрократических барьерах, так и плохом качестве этого жилья:

Появление в городе «гетто» из бывших детдомовцев, которые часто не привыкли зарабатывать деньги честным трудом, негативно влияет на криминогенную обстановку в данных районах. Об этом поднимался вопрос на муниципальном уровне. Чиновники выслушали замечания, но ситуация осталась прежней - квартиры выделяются там, где идет массовое строительство недорогого жилья (Новосибирский городской сайт, 24.02.2014).

Негативно-пассивный образ «детдомовца» становится стигмой для выпускника, у людей, проживающих с ними по соседству, могут заранее формироваться негативные ожидания при встрече или знакомстве с выпускником. Иными словами, медиа «готовят» общество к тому, что вокруг выпускников детских домов могут возникать моральные паники, связанные с их стереотипизированными образами:

У нас в подъезде в одной квартире живет сразу несколько детдомовцев. Некоторые из них ведут себя прилично, но большинство часто утраивают пьянки и драки. В одной из таких гулянок они подожгли свою квартиру и разбили окно. Так и живут в квартире с ветром. Такое соседство для законопослушных новосибирцев стало испытанием (Аргументы и факты - Новосибирск, 18.03.2015).

В публикациях охарактеризованы различные формы трудоустройства выпускника: следование формальным предписаниям («обеспечение занятости», «система общественных обязанностей»), личное сотрудничество выпускника с организациями-партнерами («защищенное производство»), организация индивидуальной работы с каждым выпускником в постинтернатный период («предоставление наставника»). Сообщения чаще окрашены позитивной тональностью: благодаря личному желанию или же по принуждению социальных служб, но выпускники интегрируются в самостоятельную жизнь через занятость и производственную деятельность. Фигура «наставника» (волонтер или профессиональный психолог) в данном контексте выступает как альтернатива опекуну, это внешний агент первичной социализации, с которым у выпускника строятся горизонтальные «братские» отношения:

Наставник обязан посвящать «младшему» не меньше часа в неделю, он учит подопечного адаптироваться к внешнему миру, чувствовать себя уверенней, смотреть на жизнь по-взрослому. Благодаря наставничеству дети становятся более общительными, самостоятельными и ответственными (Spbdeti.ru, 21.09.2015). 
В анализируемых публикациях описаны как общегосударственные программы социальной адаптации и постинтернатного сопровождения, так и непосредственные практики обучения социальным навыкам. Например, «тренировочная квартира» создается для того, чтобы в течение определенного срока (от полугода и дольше) выпускники под присмотром социальных работников и психологов обучались самостоятельной жизни. Только после экспертного заключения они могут переехать в свое собственное жилье и начать жить «по-взрослому»:

Одновременно в помещении может находиться до пяти учеников. А полный курс реабилитации рассчитан на 3 месяца. Всего в «тренировочной квартире» 4 зоны: кухонная, хозяйственная, места для отдыха и общения с психологом. Любой человек, выходящий из стен детского дома, должен иметь наставника, а таким наставником лучше всего становится психолог (Телеканал Санкт-Петербург, 15.10.2014).

Наконец, еще одна тема, связанная с адаптацией выпускников детских домов - обеспечение жильем представителей этой группы. Положительные изменения, отмеченные в прессе, связаны с тем, что государство активно предоставляет отдельные квартиры в новостройках. Вместе с тем в ряде регионов (Иркутск, Новосибирск, Приморье) публикуются истории «бездомных сирот», которые не получили жилье после выпуска из детского дома, не знали о предоставляемой государством возможности, или же лишились жилья в результате действий мошенников и «черных риелторов» (Санкт-Петербург):

Обвиняемые входили в доверие к лицам, злоупотребляющим алкоголем, а также к выпускникам детских домов, в том числе имеющим нарушения психического развития. После они получали право на распоряжение жильем потерпевших, которых, под предлогом временно пожить вне Петербурга, вывозили за пределы города, где поселяли в условиях, непригодных для проживания (Балтийское информационное агентство, 6.03.2014).

В СМИ слабо актуализирована проблема правовой социализации и грамотности выпускников, предметом внимания прессы становятся конкретные случаи нарушения прав детей-сирот, но не проекты и инициативы по юридической поддержке и консультации данной категории граждан.

$* * *$

Проведенный в работе анализ показал, что медиа склонны предлагать поляризованное и одномерное видение типизированных образов выпускников детских домов: это либо описания личного и профессионального успеха выпускников, обусловленного неустанной заботой региональных властей, либо изображение выпускников детских домов как социальных маргиналов, безработных, алкоголиков, потенциальных преступников. Между тем, реальные жизненные ситуации этой социальной категории редко становятся предметом объективного рассмотрения медиа. 
Вопросам социальной адаптации выпускников в публикациях уделяется значительно больше внимания, чем вопросам их трудоустройства. Как правило, в профессиональной адаптации могут быть заинтересованы предприятия, напрямую сотрудничающие с детскими домами, и НКО, занимающиеся организацией профориентационных мероприятий и тренингов для выпускников.

Значительная часть публикаций посвящена недостаткам и проблемам вокруг предоставления собственного жилья этой социальной группе, когда соответствующее право реализуется не в полной мере или сами выпускники не могут управлять полученной в их распоряжение собственностью. Одновременно в публикациях активно присутствует тема роли НКО и корпоративных волонтеров в адаптации выпускников детских домов и подготовке детей-сирот к самостоятельной жизни. В то же время в медиа практически не упоминается о международном опыте по профессиональной и социальной адаптации выпускников детских домов.

Анализ медийных образов выпускников детских домов позволяет дать объемную характеристику общественного восприятия этой категории граждан и определить ключевые проблемы отношения населения и прессы к ним. Стереотипный образ выпускника детского дома, несамостоятельного и пассивного, «потребительски» настроенного к предоставляемым государством льготам и пособиям, наиболее широко растиражирован в медиа. Тем самым формируется негативное отношение к выпускникам у представителей других социальных групп. Упрочняет доминирующую позицию «пассивных» медиа-образов (как с положительной, так и с отрицательной коннотацией) воспроизводимая в публикациях статистически неподтвержденная информация о том, что «только $10 \%$ выпускников детских домов нормально адаптируются ко взрослой жизни», что также отмечало экспертное сообщество (Чернова 2016:97).

Тем не менее в контексте профессиональной адаптации выпускников наравне выступает и «положительный-самостоятельный» образ, который воспроизводится в СМИ через персонализированные нарративы, публикуемые в прессе.

В заключение хотелось бы подчеркнуть, что в рамках данного исследования анализ проводился на уровне образов и тем, встречающихся внутри публикаций. Также необходимо отметить, что медийная ситуация с освещением темы детей-сирот и выпускников детских домов в настоящее время развивается очень динамично, поскольку государство и сектор НКО прикладывают усилия для улучшения положения этих социальных групп, и полученные авторами результаты характеризуют лишь один из этапов развития ситуации. Фактически, мониторинг медийной картины по данной теме может стать одним из инструментов измерения прогресса в области реализации политики в отношении детей-сирот и динамики отношения общества к выпускникам детских домов. 


\section{Список медиа-материалов, упоминаемых в тексте:}

1. Балтийское информационное агентство (baltinfo.ru) - В Петербурге суд начал рассмотрение дела «черных риелторов», отнимавших жилье у детдомовцев, 6.03.2014.

2. Фонтанка. Выпускнику детдома помогут найти работу фонд «Рауль» и Центр «Работа-і», 8.12.2014.

3. Россия 1 - Вести-Москва. Борьба за жилье воспитанников детдомов, 12.11.2015.

4. Новосибирский городской сайт. Сиротское гетто, 24.02.2014.

5. Столица FM. Очередной последний шанс, 24.01.2014.

6. Телеканал Санкт-Петербург. «Тренировочную квартиру» для выпускников детских домов открыли на Воскресенской набережной, 15.10.2014.

7. Аргументы и факты - Новосибирск. Из другого мира, 18.03.2015.

8. Spbdeti.ru - Санкт-Петербург. Партнерство НКО и власти - в интересах детей, 21.09.2015.

\section{Список источников}

Абдрашитова И.И., Паточкина Н. А. (2015) Проблемы социальной адаптации выпускников детских домов и интернатов. Вестник совета молодых ученых и специиалистов Челябинской области, (1):3-5.

Бирюкова С.С., Варламова М.А., Синявская О. В. (2013) Сиротство в России: основные тенденции и приоритеты государственной политики. СПЕРО. Социиальная политика: экспертиза, рекомендации, обзоры, (18): 57-80.

Гребенникова Е.В., Фирсова О.В. (2009) Социально-психологическая адаптация детей-сирот в приемных семьях. Вестник ТГПУ, (4): 51-55.

Дутова О.В. (2013) Социальная адаптация детей-сирот средствами социально-культурной деятельности. Современные проблемы науки и образования, (6): 1-8.

Еременко Т.В. (2014) Постинтернатное сопровождение детей-сирот и детей, оставшихся без попечения родителей, как приоритетное направление социальной защиты. Гуманитарные и социальные науки, (2): 288-291.

Коноплева И.Н., Ларин А.Н. (2014) Социальная адаптация детей, воспитывающихся в условиях детского дома. Психологическая наука и образование, (3): 125-134.

Миночкина А.С. (2012) Повышение уровня социальной адаптации детей-сирот и детей, оставшихся без попечения родителей. Гуманитарные и соииальные науки, (4): $163-173$.

Назарова И.Б. (2000) Адаптация и возможные модели мобильности сирот, М.: Московский общественный научный фонд.

Розуван А.М., Редикульцева Е.Н. (2013) Правовое регулирование обеспечения жилищных прав детей-сирот и детей, оставшихся без попечения родителей: актуальные проблемы и возможные пути их решения. Вестник ВГГУ, (1): 88-93. 
Левада Ю.А. (ред.) (1993) Советский простой человек: опыт соичиального портрета на рубеже 90-х, М.: Мировой океан.

Федеральный закон (2012) О мерах воздействия на лии, причастных к нарушениям основополагающих прав и свобод человека, прав и свобод граждан Российской Федерациии № 272-Ф3 от 28.12.2012 г.

Чернова Ж. В. (2016). Социальная адаптация выпускников детских домов. Гендерный аспект (По оценкам экспертов). Женщина в российском обществе, 4 (81): 85-100.

Шогенова Ф. З., Ханиева З.А., Шинахова М.М. (2016) Проблема социальной адаптации выпускников детских домов. Гуманитарий Юга России, (4): 286-294.

Ярская-Смирнова Е.Р., Присяжнюк Д. И., Вербилович О.Е. (2015) Приемная семья в России: публичный дискурс и мнения ключевых акторов. Журнал сочииологии и социальной антропологии, (4): 157-173.

Charmaz K. (2006) Constructing Grounded Theory: A Practical Guide through Qualitative Analysis, London: SAGE Publications. 


\section{Social Adaptation among Graduates from Orphanages in the Russian Media: A Thematic Analysis of Publications for 2014-2015}

This article considers images of orphanage graduates formed by the electronic and print media in Russia and is based on the materials from a study entitled 'The trajectories of social and professional adaptation of graduates of children's homes'. The study aimed to obtain analytical information on the socio-psychological and professional adaptation of children from Russian Orphanages. Using the automated media monitoring system 'Medialogia', the authors analyze thematic publications from seven Russian regions: Moscow, St. Petersburg, Irkutsk, Kaliningrad, Novosibirsk, Tver, and Yaroslavl. Textual analysis is based on one hundred articles selected as they enjoy the highest rating of re-quoting and republishing. A thematic map of topics constructed within this analysis shows that the main body of publications is focused on issues of compliance and violation of the orphan rights and the provision of benefits, including housing. Also attracting attention are government, NGOs and private volunteer initiatives in organising adaptation programs for orphans. On the basis of these textual materials, we have developed a thematic typology of media representations of this social group. The following types were unearthed: a positive-independent (successfully adapted and self-made orphanage graduates), a positive-passive (so-called 'adult children'), the negativeindependent ('deviants') and negative-passive (orphanhood as a social stigma). What becomes clear is that 'positive-passive' media images are the most common in the printed media at the current moment. This stigmatises orphanage graduates, positioning them as not adapted to 'real' life. The positive-independent media image occurs more rarely, usually only in the context of an orphanage graduate building a successful career. This image corresponds to specific individual biographies, while other media images tend to be devoid of personality or gender characteristics. This, the media forms a 'typical' path in the socialisation of orphan graduates that does not take into account modern pedagogical and psychological practices. These practices are associated with the individual work of educators and social workers with the orphans, who work to prepare children for release from an orphanage or boarding school. The analysis in this paper suggests that the main body of materials on orphanage graduates does not reflect the diversity of problems and challenges faced by this category of citizens.

Keywords: a graduate from orphanage, orphans, social adaptation, social service

DOI: $10.17323 / 727-0634-2017-15-3-421-434$

Roman Abramov - PhD, associate professor, Social Science Department of NRU HSE, senior researcher, Institute of Sociology Russian Academy of Science, Moscow, Russian Federation. Email: rabramov@hse.ru

Ksenia Antonova - doctorate student, Social Science Department of NRU HSE, Moscow, Russian Federation. Email: ksantonova@yandex.ru 


\section{References}

Abdrashitova I. I., Patochkina N. A. (2015) Problemy social'noj adaptacii vypusknikov detskih domov i internatov [Problems of Social Adaptation among Graduates of Orphanages and Boarding Schools]. Vestnik soveta molodyh uchyonyh i specialistov Chelyabinskoj oblasti [Bulletin of the Council of Young Scientists and Specialists of the Chelyabinsk region], (1):3-5.

Biryukova S., Varlamova M., Sinyavskaya O. (2013) Sirotstvo v Rossii: osnovnye tendentsii i prioritety gosudarstvennoy politiki [Orphanhood in Russia: Major Trends and Priorities of State Policy]. SPERO. Sotsial'naya politika: ekspertiza, rekomendatsii, obzory [SPERO. Social Policy: Expertise, Recommendations, Overviews], (18): 57-80.

Charmaz K. (2006) Constructing Grounded Theory: A Practical Guide through Qualitative Analysis, London: SAGE Publications.

Chernova Zh. V. (2016) Sotsialnaya adaptatsiya vyipusknikov detskih domov. Gendernyiy aspekt (Po otsenkam ekspertov) [Social Adaptation of Orphanage Leavers. Gender aspect (In the Estimation of Experts)]. Zhenschina v rossiyskom obschestve [Woman in Russian Society], 4 (81): 85-100.

Grebennikova E. V., Firsova O. V. (2009) Sotsialno-psihologicheskaya adaptatsiya detey-sirot $\mathrm{v}$ priemnyih semyah [Socio-Psychological Adaptation of Orphans in Foster Families]. Vestnik TGPU [TSPU Bulletin], (4): 51-55.

Dutova O.V. (2013) Sotsialnaya adaptatsiya detey-sirot sredstvami sotsialno-kulturnoy deyatelnosti [Social Adaptation of Orphans Through Socio-Cultural Activities]. Sovremennyie problemyi nauki i obrazovaniya [Modern Problems of Science and Education], 2013, (6): 1-8.

Eryomenko T.V. (2014) Postinternatnoe soprovozhdenie detej-sirot i detej, ostavshihsya bez popecheniya roditelej, kak prioritetnoe napravlenie social'noj zashchity [Post-Institutional Support for Orphans and Children Left without Parental Care, as a Priority Area of Social pProtection]. Gumanitarnye i social'nye nauki [Humanitarian and Social Sciencies], (2):288-291.

Federal Law (2012) O merakh vozdeistviia na lits, prichastnykh $k$ narusheniiam osnovopolagaiushchikh prav I svobod grazhdan Rossiyskoy Federatsii [On Measures Against Persons Involved in Violations of Fundamental Human Rights and Freedoms of Citizens of the Russian Federation] № 272-FZ from 28.12.2012.

Konopleva I.N., Larin A.N. (2014) Social'naya adaptaciya detej, vospityvayushchihsya v usloviyah detskogo doma [Social Adaptation of Children Brought up in Orphanage]. Psihologicheskaya nauka i obrazovanie [Psychology and Education], (3): 125-134.

Levada Yu.A. (ed.) (1993) Sovetskiy prostoy chelovek: opit socialnogo portreta na rubege 90- $h$ [The Soviet Simple Man: The Experience of Social Portrait at the Turn of the 90's], Moscow: Mirovoy okean.

Minochkina A. S. (2012) Povyshenie urovnya social'noj adaptacii detej-sirot i detej, ostavshihsya bez popecheniya roditelej [Raising the Level of Social Adaptation of Orphans and Children Left without Parental Care]. Gumanitarnye i social'nye nauki [Humanitarian and Social Sciencies], (4): 163-173.

Nazarova I. B. (2000) Adaptatsiya i vozmozhnyie modeli mobilnosti sirot [Adaptation and possible models of mobility of orphans], Moscow: Moscow Public Science Foundation.

Rozuvan A.M., Redikul'ceva E.N. (2013) Pravovoe regulirovanie obespecheniya zhilishchnyh prav detej-sirot i detej, ostavshihsya bez popecheniya roditelej: aktual'nye problemy i vozmozhnye puti ih resheniya [Legal Regulation of Ensuring the Housing Rights of Orphan Children and Children without Parental Support: Actual Problems and Possible Ways of their Decision]. Vestnik VGGU [VSHU Bulletin], (1): 88-93.

Shogenova F.Z., Hanieva Z. A., Shinahova M. M. (2016) Problema sotsialnoy adaptatsii vyipusknikov detskih domov [The Problem of Social Adaptation of Graduates of Orphanages]. Gumanitariy Yuga Rossii [Humanitarian of the South of Russia], (4): 286-294.

Yarskaya-Smirnova E.R., Prisyazhnyuk D. I., Verbilovich O.E. (2015) Priemnaya sem’ya v Rossii: publichnyj diskurs i mneniya klyuchevyh aktorov [Foster Family in Russia: Public Discourse and Opinions of Key Actors]. Zhurnal sociologii i social'noj antropologii [The Journal of Sociology and Social Antropology], (4): 157-173. 